\title{
An Algorithm for Production Planning Based on Supply Chain KPIs
}

\author{
D. Makajić-Nikolić, S. Babarogić, D. Lečić-Cvetković, N. Atanasov
}

\author{
Dragana Makajić-Nikolić*, Sladjan Babarogić \\ Danica Lečić-Cvetković,Nikola Atanasov \\ University of Belgrade, Faculty of Organizational Sciences \\ Serbia, 11000, Belgrade, Jove Ilića 154 \\ E-mail: gis@fon.bg.ac.rs, sladjan@fon.bg.ac.rs \\ danica@fon.bg.ac.rs, atanasovn@fon.bg.ac.rs \\ *Corresponding author
}

\begin{abstract}
This paper observe multi-period multi-product production planning problem in make-to-stock production environment with limited production capacity. Such problem is identified in Fast Moving Consumer Goods industry. The goal was to develop an algorithm for supporting dynamic production triggering decisions in relation with two supply chain key performance indicators: stock cover and customer service level. The presented approach is applied to a real example in several scenarios based on different decision criteria.

Keywords: production planning, stock cover, customer service level, heuristic algo-
\end{abstract} rithm.

\section{Introduction}

Manufacturing companies that operate in markets with changing demand are often faced with the problem of insufficient supplies of finished products. Constant fluctuations in demand and the required financial investments are influencing the decision concerning the expansion of the production capacity. Until the production capacity is actually increased, the manufacturing company has to meet the growing demand of the market with its existing production capacity.

As customer orders are received periodically and production capacities are often insufficient, it is necessary to make a choice of products which will be produced in each period. In circumstances of reduced uncertainty, it is possible to use exact methods for planning customer satisfaction by cycle, when trends in demand are predictable over a longer period of time. However, in real life this is not the case, as demand is a weekly phenomenon which requires dynamic decisionmaking. Therefore, in this paper we propose an algorithm for production planning in which decision on triggering new production is based on two supply chain key performance indicators (KPI): customer service level and stock cover.

This paper is organized in six sections. Next section describes related work with conceptual foundations. Problem description with relevant notation is presented in section tree. Heuristic algorithm for inventory planning is given in fourth section. In fifth section, numerical results with case study are described. Last section is dedicated to conclusions of the research.

\section{Related Work}

According to [5] uncertainty in production companies is categorized into environmental uncertainty - based on demand and supply uncertainty and system uncertainty (within the production process) - mainly related to production lead time, quality or failure of production process. Uncertainty depends on level of information required to perform relevant business activity based on efficient and effective management decision [4]. Responsive production planning and control 
system according to [7] is the most important factor in achieving good delivery performance and demand satisfaction in supply chain. This fact represents one of important reason to focus more on customer service as external performance, once when internal performance is already achieved on certain level.

As recognized by Shen and Daskin in [13] major cost factors associated with designing and managing a supply chain are the facility location costs, the inventory management costs, and the distribution costs, and always should be considered jointly and integrated with customer service goals. Customer service was recognized as key measure of performances within production companies according to [9] and very well described by [11]. Overall managerial question in supply chain is to determine a cost-effective customer-service level in correlation with profits and associated costs, what lead to question: Which service level will satisfy customers and what level of inventory is required? Jeffery et al. identified a range of models for determining service level and the appropriate level of inventory, process was carried out based on logistic regression to understand how performance of delivery are dependent on three independent variables: order lead time, errors in forecast, and variation in demand [6]. Further development of service level and customers selection in make-to-stock production environment was evaluated by [8], while authors in [1] evaluated possibilities for maximization of customer service with limited production capacity and customer classification.

Stock cover is key performance indicator measuring length of time that available finished goods will last if forecasted consumption happens. Available finished goods ready to be delivered to customer according to identified demand are in direct correlation with customer service level. Dellaert and Jeunet [2] evaluated stock cover in relation to behavior of lot-sizing rules in a multilevel context, when forecast demand is subject to changes within the forecast window and relevant lead time. According to [12], supply system needs to ensure adequate stock level to satisfy customers need, despite that additional stock only generates unnecessary costs, which customer has to absorb at the end. Managing customer service level and stock cover represents highly complex problem of supply chain, taking into account that these two KPIs are leading to opposite directions - high stocks assume high customer service level, and, at the same time, stock need to be minimized to deliver working capital reduction and overall company efficiency. Working capital reduction coupled with increase of sales and certain service level was evaluated by [14] through results of horizontal collaboration between supply chain members. Combined approach of managing in parallel customer service level and stocks cover was done by [3] who evaluated main obstacles in increasing pressure to reduce working capital, growing variety of products and the fulfillment of a demanding service level. Petri nets model of production planning system based on supply chain KPIs: customer service level and stock cover was presented in [10].

\section{Problem Description}

In this paper we observe multi-period multi-product inventory planning problem in make-tostock production environment with limited production capacity. We started from a real example of Fast Moving Consumer Goods (FMCG) in Serbia. Choice of products than will be produced should be made in each period (cycle). This decision is based on two key performance indicators: Customer service level (CSL) and Stock cover (SC). The basic assumptions of the observed problem can be divided into three groups as follows.

- Customers orders assumptions:

- Customers place orders in all or almost all of the cycles;

- Demand for each product is uneven and is known only for one cycle in advance; 
- Demand for each product represents the sum of all customers orders for delivery in given cycle;

- Decision about fulfillment is done in given cycle when all orders are received;

- Demand is fulfilled from the stock, entirely or partially, depending on the inventory level;

- Orders that have not been fully met in the reporting cycle shall not be compensated in the subsequent cycles - no reordering policy;

- Inventory assumptions:

- If the incoming customer orders in a single cycle do not exceed the available stock of finished goods, the allocation is complete and all customer orders are fulfilled, while any surplus products are stored for the next cycle;

- Inventory holding costs are neglected;

- Total inventory capacity is not limited. Therefore, inventory planning problem becomes production planning problem;

- Production assumptions:

- The production capacity is limited and constant in the entire period;

- There is no possibility for production extension in medium term planing horizon;

- Due to specific production technology requirements, outscoring with acceptable costs is not possible; ;

- Lot sizes of products are different and fixed;

- Production time and costs are neglected due to homogeneity of the products;

In order to formulate the algorithm and based on the problem assumptions, the following notation will be used in the remaining of the paper:

- $n$ - number of products;

- $m$ - number of periods in the observed time horizon;

- mcsl - minimally acceptable customer service level;

- $m s c$ - minimally acceptable stock cover;

- $l_{i}$ - lot size of $i$-th product, $i=1, \ldots, n$;

- $C$ - available production capacities in each period;

- $S_{i}$ - inventory level of $i$-th product at the beginning of the observed time horizon, $i=1, \ldots, \mathrm{n}$;

- $t_{i j}$ - demand for $i$-th product in $j$-th period, $i=1, \ldots, n, j=1, \ldots, m$;

- $p_{i j}$ - forecast for $i$-th product in $j$-th period, $i=1, \ldots, n, j=1, \ldots, m$;

Forecasts are calculated using $k$-periods moving average:

$$
p_{i j}=\frac{1}{k} \sum_{u=1}^{k} t_{i j-u}
$$




\section{Algorithm}

The goal of the algorithm (Fig.1) is to support two-phased decision making process. The result of the first phase is a list of products that should be produced in observed period, where decision is made based on calculated KPIs (CSL and SC). In the second phase, the algorithm forms a list of products that will be produced, applying one of four defined criteria: minimal CSL, minimal SC, maximal capacity utilization and maximal number of products and taking into account the available capacities. The proposed algorithm has polynomial complexity.

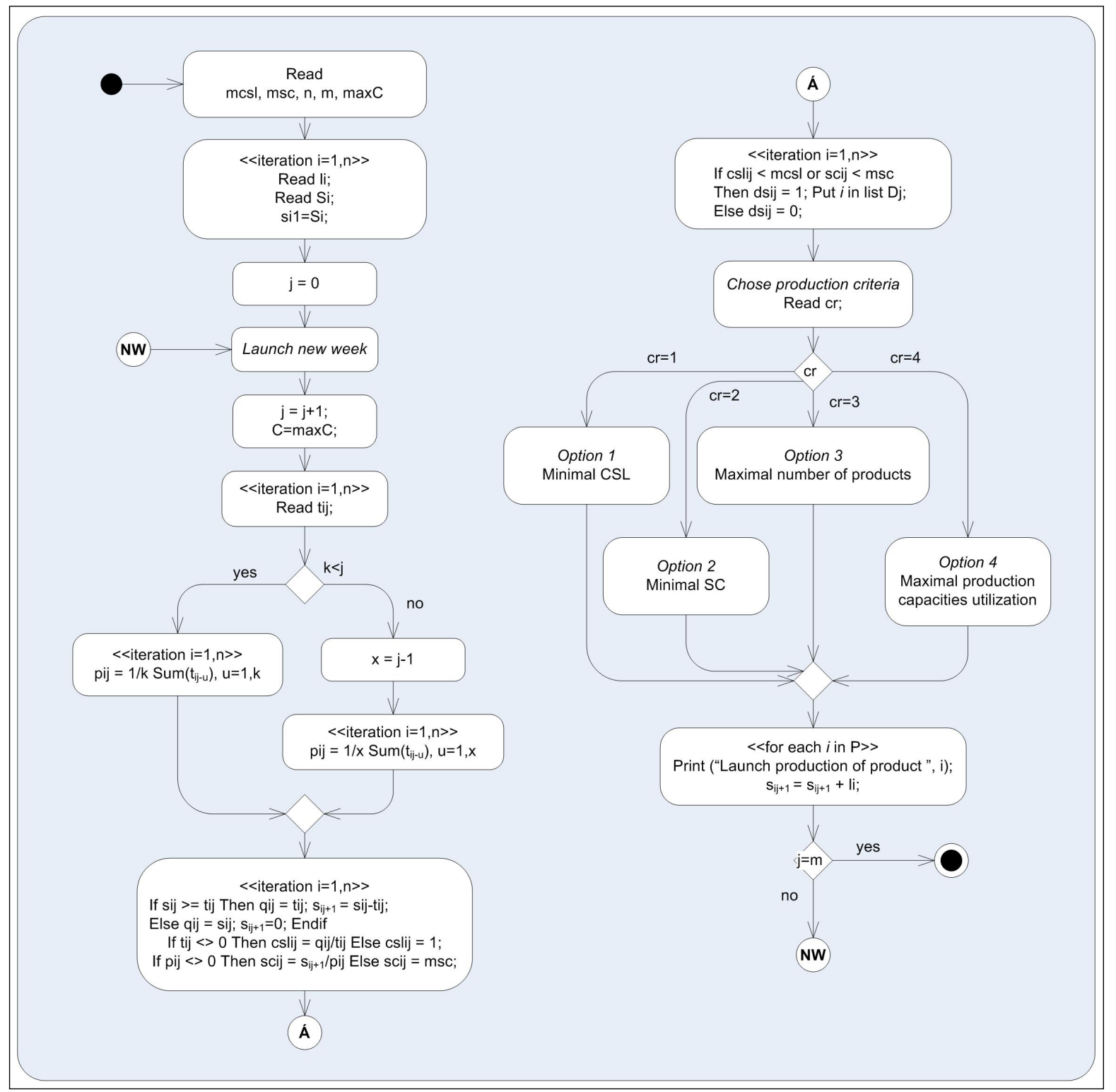

Figure 1: Algorithm represented as UML 2.0 Activity Diagram

Using parameters defined in problem description section, the following variables are calculated in each period.

- $s_{i j}$ is a stock level of $i$-th product in $j$-th period, $i=1, \ldots, n, j=1, \ldots, m$.

- $q_{i j}$ - delivered quantity of $i$-th product in $j$-th period, $i=1, \ldots, n, j=1, \ldots, m$. The delivered 
quantity of each product depends on demand and stock level as follows:

$$
q_{i j}=\left\{\begin{array}{ll}
t_{i j}, & s_{i j} \geq t_{i j} \\
s_{i j}, & \text { otherwise }
\end{array}, i=1, \ldots, n, j=1, \ldots, m\right.
$$

- $c s l_{i j}=q_{i j} / t_{i j}$ - customer service level of $i$-th product achieved in $j$-th period, $i=1, \ldots, n$, $j=1, \ldots, m$, observed as fill rate, indicates ratio between delivered and ordered quantity;

- $s c_{i j}=s_{i j} / p_{i j}$ - stock cover for $i$-th product provided in $j$-th period, $i=1, \ldots, n, j=1, \ldots, m$.

Based on variables values, two decisions must be made sequentially for each product in each period.

1. The first decision refers to the request for the production of the $i$-th product in $j$-th period $\left(d s_{i j}, i=1, \ldots, n, j=1, \ldots, m\right)$. Request for production is initiated if any of the indicators $\left(c s l_{i j}\right.$ or $\left.s c_{i j}\right)$ falls below the minimum value, i.e:

$$
d s_{i j}= \begin{cases}1 \text { (production requested) } \quad, \quad c s l_{i j}<m c s l \text { or } s c_{i j}<m s c \\ 0 \text { (production not requested), } & \text { otherwise }\end{cases}
$$

for $i=1, \ldots, n, j=1, \ldots, m$.

As a result, a set of all products that should be produced during $j$-th period is obtained: $D_{j}=\left\{i \mid d s_{i j}=1\right\}$.

2. Since the available production capacities are limited without possibilities of extension in short term and often insufficient, the second decision is related to a choice of products that will be produced. This choice can be made using several criteria: minimal CSL, maximal number of product and maximal production capacities utilization. Let $P$ be a set of chosen product. In the following, each of the above criteria for generating the set $P$ will be described in detail.

\section{Options 1 and 2 - minimal CSL and minimal SC}

According to the first two criteria, the higher priority is given to the products with smaller demand satisfaction or with smaller stock cover in the previous period. These criteria should be used in the case of large variations in the customer service level or stock cover among products. For each time period $j$, the following procedure is applied.

Initialization: $P=\emptyset$.

Do

Find $i *$ such that $c s l_{i * j}=\min \left\{k p i_{i j} \mid i \in D\right\}$.

If $l_{i *} \leq C$ then $i * \rightarrow P, C:=C-l_{i *}$ endif.

$D_{j}:=D j i *$

until $C=0$ or $D_{j}=\emptyset$.

Variable $k p i_{i j}$ represents key performance indicator $c s l_{i j}$ (Option 1) or $s c_{i j}$ (Option 2) depending on chosen criteria.

The output of the procedure is the set $P$ which contains the indexes of the products that will be produced. 
Options 3 and 4 - maximal number of products and maximal production capacities utilization

Maximal number of products can be used as criterion when company wants to cover the market with wide variety of products. When there is a large lack of capacity, maximal production capacities utilization should be used as a criterion. For each period $j$, these two criteria can be modeled as following knapsack problem:

$$
\begin{aligned}
& \max \sum_{u \in D_{j}} a_{i} \cdot x_{i} \\
& \text { s.t. } \\
& \sum_{u \in D_{j}} l_{i} \cdot x_{i} \leq C
\end{aligned}
$$

where:

$$
\begin{gathered}
x_{i}=\left\{\begin{array}{ll}
1, & \text { if the product } i \text { is chosen to be produced } \\
0, & \text { otherwise }
\end{array}, i=1, \ldots, n\right. \\
a_{i}=\left\{\begin{array}{ll}
1, & \text { if the criterion is number of products (Option 3) } \\
l_{i}, & \text { if the criterion is capacities utilisation (Option 4) }
\end{array}, i=1, \ldots, n\right.
\end{gathered}
$$

After obtaining the optimal results, set of products that will be produced, $P$, contains all products $i$ such that $x_{i}=1$.

\section{Computational Results and Discussion}

The algorithm has been applied on real data calculation based on 28 weeks observation, made for four products of real, medium sized Fast Moving Consumer Goods (FMCG) company. Installed production capacity is 290 units per period (week), while lot sizes are 120, 110, 170 and 50 units for products p1, p2, p3 and p4, respectively. Customers' orders are shown in Table 1. Forecast is calculated based on three-week moving average (equation 1).

Table 1: Customers' orders for 28 weeks

\begin{tabular}{crrrrrrrrrr}
\hline Product & w1 & w2 & w3 & w4 & w5 & w6 & w7 & w8 & w9 & w10 \\
\hline p1 & 35 & 75 & 29 & 48 & 40 & 52 & 29 & 59 & 67 & 82 \\
p2 & 50 & 122 & 55 & 129 & 40 & 346 & 70 & 102 & 112 & 16 \\
p3 & 68 & 112 & 48 & 94 & 62 & 357 & 75 & 98 & 124 & 18 \\
p4 & 6 & 23 & 27 & 57 & 0 & 30 & 45 & 38 & 56 & 69 \\
\hline Product & w11 & w12 & w13 & w14 & w15 & w16 & w17 & w18 & w19 & w20 \\
\hline p1 & 96 & 88 & 45 & 23 & 16 & 31 & 166 & 16 & 34 & 137 \\
p2 & 83 & 28 & 40 & 28 & 53 & 100 & 70 & 36 & 49 & 292 \\
p3 & 11 & 25 & 49 & 34 & 63 & 117 & 112 & 48 & 69 & 325 \\
p4 & 14 & 67 & 171 & 27 & 4 & 66 & 5 & 8 & 15 & 110 \\
\hline Product & w21 & w22 & w23 & w24 & w25 & w26 & w27 & w28 & & \\
\hline p1 & 83 & 23 & 110 & 156 & 109 & 102 & 34 & 69 & & \\
p2 & 95 & 119 & 447 & 56 & 154 & 34 & 112 & 107 & & \\
p3 & 162 & 128 & 314 & 93 & 156 & 88 & 115 & 128 & & \\
p4 & 3 & 86 & 153 & 1 & 1 & 1 & 0 & 25 & & \\
\hline
\end{tabular}


Based on descriptive statistical analysis for the observed period, it can be concluded that products $\mathrm{p} 2$ and $\mathrm{p} 3$ had the highest average demand (105.18 and 110.46, respectively) but also the highest standard deviation of demand (99.81 and 87.69, respectively). In addition, these two products had three major demand peaks in the same periods (w6, w20 and w23). These facts lead us to the conclusion that production capacity will remain mean issue in the future.

Developed algorithm can be used at operational and strategic level. Operational level is related to the decision of production requesting and launching. Table 2 illustrates the operational decisions. It shows the decisions for the product $\mathrm{p} 1$ in the entire period when minCSL criterion is used. The first column represents the weeks of the observed period. The second and third columns give the orders and the forecasts per weeks for product p1. Columns labeled as SB and SA shows the stock level before and after product delivery while the next column gives the amount of delivered quantities. Columns CSL and SC show calculated values for customer service level and stock cover per periods. The last three columns represent the decisions about requested, confirmed and missed production, respectively. In the last row of the Table 2, the values of total delivered quantities, average SCL and SC, and total number of production request, conformation and missing are given.

Table 2: Production decisions for 28 weeks for $\mathrm{p} 1$ and minCSL criterion

\begin{tabular}{crrrrrrrrrr}
\hline Time & Order & Forecast & SB & SA & delivered & CSL & SC & PR & PC & PM \\
\hline w1 & 35 & 36 & 110 & 75 & 35 & 1 & 2.083 & & & \\
w2 & 75 & 66 & 75 & 0 & 75 & 1 & 0 & 1 & 1 & \\
w3 & 29 & 95 & 120 & 91 & 29 & 1 & 0.958 & 1 & 1 & \\
w4 & 48 & 46 & 211 & 163 & 48 & 1 & 3.518 & & & \\
w5 & 40 & 51 & 163 & 123 & 40 & 1 & 2.428 & & & \\
w6 & 52 & 39 & 123 & 71 & 52 & 1 & 1.821 & 1 & & 1 \\
w7 & 29 & 47 & 71 & 42 & 29 & 1 & 0.9 & 1 & 1 & \\
w8 & 59 & 40 & 162 & 103 & 59 & 1 & 2.554 & & & \\
w9 & 67 & 47 & 103 & 36 & 67 & 1 & 0.771 & 1 & & 1 \\
w10 & 82 & 52 & 36 & 0 & 36 & 0.439 & 0 & 1 & 1 & \\
w11 & 96 & 69 & 120 & 24 & 96 & 1 & 0.346 & 1 & 1 & \\
w12 & 88 & 82 & 144 & 56 & 88 & 1 & 0.686 & 1 & 1 & \\
w13 & 45 & 89 & 176 & 131 & 45 & 1 & 1.477 & 1 & 1 & \\
w14 & 23 & 76 & 251 & 228 & 23 & 1 & 2.987 & & & \\
w15 & 16 & 52 & 228 & 212 & 16 & 1 & 4.077 & & & \\
w16 & 31 & 28 & 212 & 181 & 31 & 1 & 6.464 & & & \\
w17 & 166 & 23 & 181 & 15 & 166 & 1 & 0.643 & 1 & 1 & \\
w18 & 16 & 71 & 135 & 119 & 16 & 1 & 1.676 & 1 & & 1 \\
w19 & 34 & 71 & 119 & 85 & 34 & 1 & 1.197 & 1 & 1 & \\
w20 & 137 & 72 & 205 & 68 & 137 & 1 & 0.944 & 1 & & 1 \\
w21 & 83 & 62 & 68 & 0 & 68 & 0.819 & 0 & 1 & 1 & \\
w22 & 23 & 85 & 120 & 97 & 23 & 1 & 1.146 & 1 & & 1 \\
w23 & 110 & 81 & 97 & 0 & 97 & 0.882 & 0 & 1 & & 1 \\
w24 & 156 & 72 & 0 & 0 & 0 & 0 & 0 & 1 & 1 & \\
w25 & 109 & 96 & 120 & 11 & 109 & 1 & 0.114 & 1 & & 1 \\
w26 & 102 & 125 & 11 & 0 & 11 & 0.1080 & 0 & 1 & 1 & \\
w27 & 34 & 122 & 120 & 86 & 34 & 1 & 0.703 & 1 & & 1 \\
w28 & 69 & 82 & 86 & 17 & 69 & 1 & 0.208 & 1 & 1 & \\
\hline Total & & & & & 1533 & 0.902 & 1.346 & 21 & 13 & 8 \\
\hline & & & & & & & & & &
\end{tabular}


Table 3 shows requesting for productions and decisions about confirmation or missing the production for all four products in the entire observed period. Abbreviation used in the Table3 are the same as in the Table 2. In the last row total numbers of production request, conformation and missing are given for all the products. Production requests for all four products appeared in 9 out of 28 weeks and in 5 of them only two product were produced.

Table 3: Production decisions for 28 weeks for all products and minCSL criterion

\begin{tabular}{c|ccc|ccc|ccc|ccc}
\hline & \multicolumn{3}{|c|}{$\mathrm{p} 1$} & & $\mathrm{p} 2$ & \multicolumn{3}{|c|}{$\mathrm{p} 3$} & \multicolumn{3}{c}{$\mathrm{p} 4$} & \\
\hline Time & PR & PC & PM & PR & PC & PM & PR & PC & PM & PR & PC & PM \\
\hline w1 & & & & 1 & 1 & & 1 & 1 & & & & \\
w2 & 1 & 1 & & 1 & 1 & & & & & & & \\
w3 & 1 & 1 & & 1 & & 1 & 1 & 1 & & & & \\
w4 & & & & 1 & 1 & & & & & 1 & 1 & \\
w5 & & & & 1 & 1 & & 1 & 1 & & 1 & & 1 \\
w6 & 1 & & 1 & 1 & 1 & & 1 & 1 & & & & \\
w7 & 1 & 1 & & 1 & 1 & & 1 & & 1 & 1 & 1 & \\
w8 & & & & 1 & 1 & & 1 & 1 & & 1 & & 1 \\
w9 & 1 & & 1 & 1 & & 1 & 1 & 1 & & 1 & 1 & \\
w10 & 1 & 1 & & 1 & 1 & & & & & 1 & 1 & \\
w11 & 1 & 1 & & 1 & 1 & & & & & 1 & 1 & \\
w12 & 1 & 1 & & 1 & 1 & & & & & 1 & 1 & \\
w13 & 1 & 1 & & & & & & & & 1 & 1 & \\
w14 & & & & & & & & & & 1 & 1 & \\
w15 & & & & & & & 1 & 1 & & 1 & 1 & \\
w16 & & & & 1 & 1 & & 1 & & 1 & 1 & 1 & \\
w17 & 1 & 1 & & 1 & & 1 & 1 & 1 & & & & \\
w18 & 1 & & 1 & 1 & 1 & & 1 & 1 & & & & \\
w19 & 1 & 1 & & 1 & 1 & & & & & & & \\
w20 & 1 & & 1 & 1 & & 1 & 1 & 1 & & 1 & 1 & \\
w21 & 1 & 1 & & 1 & 1 & & 1 & & 1 & 1 & 1 & \\
w22 & 1 & & 1 & 1 & 1 & & 1 & 1 & & 1 & & 1 \\
w23 & 1 & & 1 & 1 & 1 & & 1 & 1 & & 1 & & 1 \\
w24 & 1 & 1 & & 1 & 1 & & 1 & & 1 & 1 & 1 & \\
w25 & 1 & & 1 & 1 & 1 & & 1 & 1 & & 1 & & 1 \\
w26 & 1 & 1 & & 1 & 1 & & 1 & & 1 & 1 & 1 & \\
w27 & 1 & & 1 & 1 & 1 & & 1 & 1 & & & & \\
w28 & 1 & 1 & & 1 & & 1 & 1 & 1 & & & & \\
\hline Total & 21 & 13 & 8 & 25 & 20 & 5 & 20 & 15 & 5 & 19 & 14 & 5 \\
\hline
\end{tabular}

At strategic level, a decision about the most appropriate criterion can be made using the proposed algorithm. Computational results for all observed products and all four decision criteria are given in Table 4. Column "Delivered" represents quantities which are delivered during entire period per product. Columns "csl" and "sc" represents KPIs. The last column represents the percent of launched production requests.

The percentages of capacity utilizations for options 1, 2, 3 and 4, are $0.863,0.857,0.872$ and 0.817 , respectively. After algorithm results presentation, management of the observed company considers option 1 the most appropriate. Applying the first option (min CSL) in algorithm, the highest level of CSL and the largest quantity of delivered products are provided. As positive side effect, high level of capacity utilization is achieved even that was not included as criterion 
Table 4: Summary results

\begin{tabular}{|c|c|c|c|c|c|}
\hline & & Delivered & csl & $\mathrm{sc}$ & $\operatorname{card}(\mathrm{P}) / \operatorname{card}(\mathrm{D})$ \\
\hline \multirow[t]{5}{*}{ Option 1 (min csl) } & p1 & 1533 & 0.90 & 1.35 & 0.714 \\
\hline & p2 & 2263 & 0.91 & 0.98 & 0.800 \\
\hline & p3 & 2538 & 0.89 & 1.29 & 0.750 \\
\hline & $\mathrm{p} 4$ & 778 & 0.83 & 7.36 & 0.737 \\
\hline & & total 7112 & avg 0.88 & avg 2.75 & avg 0.753 \\
\hline \multirow[t]{5}{*}{ Option 2 (min sc) } & p1 & 1533 & 0.90 & 1.40 & 0.619 \\
\hline & p2 & 2240 & 0.93 & 1.05 & 0.833 \\
\hline & p3 & 2488 & 0.89 & 1.03 & 0.682 \\
\hline & $\mathrm{p} 4$ & 728 & 0.77 & 7.30 & 0.684 \\
\hline & & total 6989 & $\operatorname{avg} 0.87$ & $\operatorname{avg} 2.70$ & avg 0.709 \\
\hline & p1 & 1823 & 0.99 & 1.78 & 1 \\
\hline \multirow{4}{*}{ (max capacity utilization) } & p2 & 1687 & 0.67 & 0.67 & 0.600 \\
\hline & p3 & 2940 & 0.98 & 2.44 & 1 \\
\hline & $\mathrm{p} 4$ & 575 & 0.59 & 2.08 & 0.591 \\
\hline & & total 7025 & avg 0.81 & $\operatorname{avg} 1.74$ & avg 0.765 \\
\hline Option 4 & $\mathrm{p} 1$ & 1823 & 0.99 & 1.78 & 1 \\
\hline \multirow[t]{4}{*}{ (max number of product) } & p2 & 1690 & 0.73 & 0.76 & 0.625 \\
\hline & p3 & 2263 & 0.80 & 1.32 & 0.619 \\
\hline & $\mathrm{p} 4$ & 879 & 0.91 & 11.20 & 1 \\
\hline & & total 6655 & avg 0.86 & avg 3.76 & avg 0.782 \\
\hline
\end{tabular}

in option 1. Although the average results in the last column indicate the similar percentages of launched production requests for all four options, detailed analysis by products shows that even nearly $40 \%$ production requests for some products remain unrealized in options 3 and 4 . Considering this indicator in the last column, option 1 gives the most balanced values.

\section{Conclusions}

The aim of this paper was to develop a heuristic algorithm for multi-period production planning based on supply chain KPIs: customer service level and stock cover. Analyzing FMCG company with limited production capacities, two important decisions are recognized in each period: which products should be produced (production requesting) and which product can be produced (production launching). The proposed algorithm provides support for both decisions. The first decision is based on two used KPIs, while the second decision can be made by using one of four criteria: minCSL, minSC, maximal capacity utilization and maximal number of products.

Developed algorithm was applied in real FMCG where option 1 was chosen as the most appropriate according to their business policy. However, the main advantage of the algorithm is the fact that it offers a choice among four different decision criteria based on company's business policies. It can be extended in order to generate demand forecast based on different forecasting techniques and adding new KPI: demand forecast accuracy, which will be used for evaluation of the impact of forecast accuracy on customer service level and stock cover variations. 


\section{Bibliography}

[1] Babarogić, S.; Makajić-Nikolić, D.; Lečić-Cvetković, D.; Atanasov N. (2012); Multi-period Customer Service Level Maximization under Limited Production Capacity, International Journal of Computers Communications \& Control, ISSN 1841-9836, 7(5): 798-806.

[2] Dellaert N.P., Jeunet J. (2003); Demand forecast accuracy and performance of inventory policies under multi-level rolling schedule environments, Research at International Institute of Infonomics, Heerlen, The Netherlands.

[3] Fernandez, R.; Gouveia, J. B.; Pinho, C. (2010); Overstock - A Real Option Approach, Journal of Operations and Supply Chain Management, ISSN 1984-3046, 3(1): 98-107.

[4] Galbraith, J. R. (1973); Designing Complex Organizations, Reading, MA: Addison-Wesley.

[5] Ho, C. (1989); Evaluating the Impact of Operating Environments on MRP System Nervousness, Int J Prod Res, ISSN 0020-7543, 27(7): 1115-1135.

[6] Jeffery M.M., Butler J.R., Malone C.L. (2008); Determining a cost-effective customer service level, Supply Chain Management: An International Journal, 13: 225-232.

[7] Lane, R.; Szwejczewski, M. (2000); The Relative Importance of Planning and Control Systems in Achieving Good Delivery Performance, Prod Plan Control, ISSN 0953-7287, 11(5): 422433.

[8] Lečić-Cvetković, D.; Atanasov, N.; Babarogić, S. (2010); An Algorithm for Customer Order Fulfillment in a Make-to-Stock Manufacturing System, International Journal of Computers Communications \& Control, ISSN 1841-9836, 5(5): 983-791.

[9] Lin, J.; Chen, J.H. (2005); Enhance Order Promising with ATP Allocation Planning Considering Material and Capacity Constraints, Journal of the Chinese Institute of Industrial Engineers, ISSN 1017-0669, 22(4): 282-292.

[10] Makajić-Nikolić, D.; Lečić-Cvetković; Atanasov, N.; Babarogić, S. (2013); An Approach to Production Planning for Supply Chain Performance Improvements, Proceedings of XI Balkan Conference on Operational Research, ISBN 978-86-7680-285-2, 357-366.

[11] Meyr, H. (2009); Customer Segmentation, Allocation Planning and Order Promising in Make-to-Stock Production, OR Spectrum, ISSN 0171-6468, 31(1): 229-256.

[12] Okulewicz, J. (2009); Verification of a Service Level Estimation Method, Total Logistics Management, ISSN 1689-5959, 2: 67-78.

[13] Shen Z-Y.M., Daskin M. (2005); Trade-offs Between Customer Service and Cost in Integrated Supply Chain Design, Manufacturing and Service Operations Management, 7(3): 188-207.

[14] Wadhwa S., Kanda A., Bhoon K.S. (2006); Bibhushan Impact of Supply Chain Collaboration on Customer Service Level and Working Capital, Global Journal of Flexible Systems Management, 7(1-2): 27-35. 